\title{
Dendritic cell vaccination, immune regulation, and clinical outcomes in ovarian cancer
}

\author{
Hannah E. Goyne ${ }^{1}$ and Martin J. Cannon ${ }^{2,3 *}$ \\ 1 Department of Pathology, University of Arkansas for Medical Sciences, Little Rock, AR, USA \\ ${ }^{2}$ Department of Microbiology and Immunology, University of Arkansas for Medical Sciences, Little Rock, AR, USA \\ ${ }^{3}$ Department of Obstetrics and Gynecology, University of Arkansas for Medical Sciences, Little Rock, AR, USA
}

\section{Edited by:}

Kristian Michael Hargadon,

Hampden-Sydney College, USA

\section{Reviewed by:}

Amedeo Amedei, University of

Florence, Italy

Pedro Berraondo, Centro para la

Investigación Médica Aplicada, Spain

*Correspondence:

Martin J. Cannon, Department of Microbiology and Immunology,

University of Arkansas for Medical

Sciences, 4301 West Markham, Little

Rock, AR 72205, USA

e-mail:mjcannon@uams.edu
Clinical optimism for dendritic cell vaccination against ovarian cancer has been tempered by the knowledge that tumors avail themselves of multiple mechanisms of immune evasion, thus blunting the efficacy of therapeutic vaccination. Mechanisms of immune suppression include infiltration by regulatory $T$ cells (Treg) and myeloid suppressor cell populations, expression of co-inhibitory receptors, and expression of indoleamine 2,3-dioxygenase (IDO). Expression of both $\mathrm{B} 7-\mathrm{H} 1$ and IDO are associated with differentiation and recruitment of Treg, and clinical studies have shown that each of these mechanisms correlates independently with increased morbidity and mortality in ovarian cancer patients. In sharp contrast, recent studies have indicated that Th17 cell infiltration in ovarian cancer correlates with improved patient outcomes and prolonged overall survival. Given that IDO plays a pivotal role in the balance between Treg and Th17 immunity, elucidation of the mechanisms that regulate IDO activity and immune suppression may lead to novel adjuvants to boost the clinical efficacy of dendritic cell vaccination against ovarian cancer and other malignancies.

Keywords: ovarian cancer, regulatory $\mathrm{T}$ cells, Th17 T cells, dendritic cells, indoleamine 2,3-dioxygenase

\section{THE CLINICAL PROBLEM}

Clinical studies have shown that the immune system plays an active and possible critical role in the pathogenesis of ovarian cancer, disease progression, and overall survival. Of the positive parameters, CD3 T cell infiltration has been associated with prolonged survival (1). A notable point from this investigation was that patients with significant $\mathrm{T}$ cell infiltration in their tumors were more likely to be optimally debulked during surgery provided an indication that $\mathrm{T}$ cells may limit regional spread of the disease. In contrast with these positive findings, the majority of studies have highlighted multiple mechanisms of immune suppression that correlate with poor patient outcomes in ovarian cancer.

Regulatory T cells (Treg) infiltration has been widely noted as a negative correlate of clinical outcomes for many malignancies, and ovarian cancer is no exception. Curiel and colleagues showed that Treg infiltration in ovarian cancer correlates with a poor prognosis and increased mortality (2). Other investigators have shown that high expression of Foxp3 (a transcription factor associated with a Treg phenotype) is an independent prognostic indicator for reduced survival (3), and that a high CD8/Treg ratio is associated with more favorable outcomes (4). Further mechanisms that contribute to the immunosuppressed state include expression of PD-L1 (B7-H1), which can promote T cell anergy and apoptosis through engagement of PD-1 expressed by effector $\mathrm{T}$ cells $(5,6)$ and expression of indoleamine 2,3-dioxygenase (IDO). Expression of both B7-H1 and IDO are associated with differentiation and recruitment of Treg (7-9), and clinical studies have shown that each of these mechanisms correlates independently with increased morbidity and mortality in ovarian cancer patients (10-12). Immune suppression in the tumor micro-environment is also likely to present a formidable barrier to the clinical efficacy of therapeutic tumor vaccination, including dendritic cell (DC) vaccination.

In sharp contrast with the evidence that Treg infiltration is associated with poor outcomes in ovarian cancer, Th17 T cell infiltration correlates with more favorable clinical outcomes (13). Furthermore, tumor-infiltrating Th17 cells were negatively associated with Treg infiltration, suggesting a reciprocal relationship between these subsets. These observations have led to the question of whether therapeutic benefit would accrue from induction or expansion of Th17 cells, either through DC vaccination, other types of tumor vaccines or adoptive immunotherapy $(14,15)$.

\section{CAN DENDRITIC CELLS STIMULATE TH17 RESPONSES} AGAINST OVARIAN CANCER?

The tumor micro-environment can modify DC function through multiple mechanisms, usually resulting in inhibition of DC activation and maturation, and the induction of immunosuppressive DC and related myeloid cell populations (16). Tumor inhibition of DC function can also have an impact on therapeutic DC vaccines, indicating the need for DC vaccines with the capability to redirect $\mathrm{T}$ cell immunity from immune suppression to pro-inflammatory anti-tumor responses. Several lines of evidence have pointed to a crucial role for MAPK signaling pathways in regulation of proinflammatory versus tolerogenic or immunosuppressive DC function. Notably, Jackson and colleagues demonstrated that blockade 
of MEK 1/2 and ERK MAPK signaling restores tumor-mediated inhibition of DC function and promotes IL-12 production and Th1 T cell responses, whereas inhibition of p38 MAPK increases signal transduction through ERK $1 / 2$ and blocks IL-12 production (17). In similar vein, p38 MAPK signaling in DC up-regulates IL-10 expression and induces tolerance in a mouse model of melanoma, resulting in suppression of anti-tumor $\mathrm{T}$ cell response, whereas inhibition of p38 signaling restored the ability of DC to stimulate T cell responses (18). The observation that p38 inhibition or MEK/ERK activation restores DC function in myeloma patients provides further evidence that p38 blockade may be of therapeutic benefit (19).

With respect to the balance between Treg versus Th17 immunity, studies in mice have shown that p38 inhibition attenuates Treg induction by DC and enhances the efficacy of DC vaccination and anti-tumor immunity (20), whereas blockade of the ERK pathway suppresses DC-driven Th17 responses (21). Collectively, these results suggest that preferential signaling though the ERK pathway may favor a switch from DC induction of Treg responses to Th17 differentiation and expansion.

In humans, treatment of ovarian tumor antigen-loaded, cytokine-matured DC with a combination of IL-15 and a p38 MAPK inhibitor offers potent synergy in antagonism of Treg induction and redirection toward Th17 responses that correlate with strong $\mathrm{CD}^{+}$CTL activation (22). Tumor antigen-specific $\mathrm{CD}^{+}{ }^{+} \mathrm{T}$ cells secreted high levels of IL-17 and showed reduced expression of CTLA-4, PD-1, and Foxp3 following activation with IL-15/p38 inhibitor-treated DC. It was further shown that modulation of $\mathrm{p} 38$ MAPK signaling was associated with reduced expression of PD-L1 (B7-H1), loss of IDO activity, and increased phosphorylation of ERK1/2 MAPK. These observations afford an opportunity to develop innovative DC vaccination strategies to boost Th17 immunity in ovarian cancer patients.

\section{IDO AND THE BALANCE OF POWER BETWEEN TREG AND TH17 IMMUNITY}

Several lines of investigation have pointed to a pivotal role for IDO in directing Treg or Th17 responses in tumor immunity. In humans, IDO-expressing mature DC induce proliferation of $\mathrm{CD} 4{ }^{+} \mathrm{CD} 25^{+}$Foxp $^{+}$Treg (9) and parallel studies in mice have shown that IDO activates Treg and inhibits their conversion to Th17-like $\mathrm{T}$ cells $(8,23)$. The pathways involved in control of Treg/Th17 differentiation by IDO have hitherto been obscure, but recent studies have revealed a relationship between IDO function and the aryl hydrocarbon receptor (AhR) on DC and T cells. Binding of the AhR promotes the generation of Treg (24-26) and AhR ligand-specific interactions may control the balance between Treg and Th17 differentiation $(27,28)$. Remarkably, the tryptophan catabolite kynurenine produced by IDO is a natural ligand for $\operatorname{AhR}(29,30)$, thus creating a mechanism by which IDO promotes generation of Treg.

The AhR is also expressed by DC, and is required for induction of IDO expression, thus creating a feedback loop via kynurenine that maintains DC regulatory function (31). DC from $\mathrm{AhR}^{-1-}$ mice lacked IDO and inhibited Treg development and promoted Th17 generation from naïve T cells. Addition of exogenous kynurenine restored the generation of Foxp $3^{+}$Treg and diminished Th17

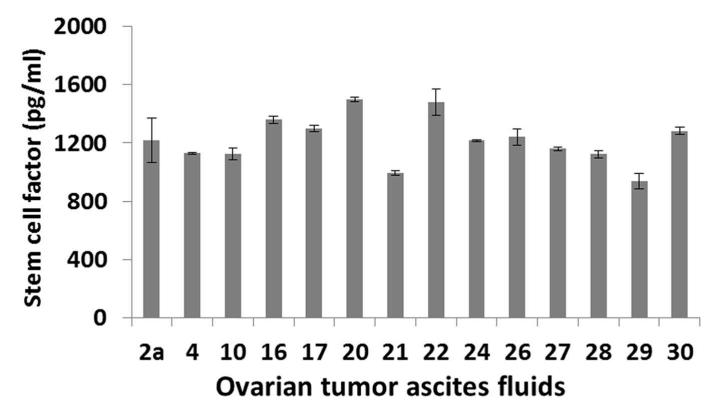

FIGURE 1 | SCF levels in primary ovarian tumor ascites fluids. Samples from 14 patients with a confirmed diagnosis of epithelial ovarian cancer were tested by ELISA.

differentiation, reinforcing the hypothesis that IDO, kynurenine, and AhR regulate the balance between Treg and Th17 immunity.

The mechanisms by which IDO expression is regulated in ovarian tumors and tumor-associated myeloid cells are largely unknown. One potential mechanism is that IDO activity may be driven by c-KIT signaling following binding of stem cell factor (SCF), which is secreted by ovarian tumors (32-34). This proposal is based in part on recent studies showing that IDO expression can be blocked by inhibitors of c-KIT or mTOR (downstream of the c-KIT-PI3K-AKT pathway), with resultant potentiation of antitumor T cell responses (35). Furthermore, siRNA knockdown of SCF or blockade of c-KIT can inhibit myeloid-derived suppressor cell expansion, Treg development and tumor angiogenesis, producing a synergistic therapeutic effect in combination with immunotherapy (36). Given that SCF is abundantly present in ovarian tumor ascites (Figure 1), these findings raise the possibility that similar mechanisms of immune regulation may prevail in ovarian cancer.

Collectively, these observations allow formulation of an innovative model in which SCF binds c-KIT expressed by ovarian tumor cells or infiltrating myeloid cells, resulting in IDO expression. Kynurenine produced by IDO activity binds AhR on T cells and induces Treg differentiation (Figure 2). Drugs that block c-KIT signaling or IDO function may inhibit Treg recruitment and alleviate immune suppression by shifting the balance in favor of Th17 $\mathrm{T}$ cell differentiation and expansion.

\section{INNOVATIVE STRATEGIES FOR ALLEVIATION OF IDO-MEDIATED IMMUNE SUPPRESSION}

Although the ability to manipulate the functional plasticity of DC to stimulate Th17 responses against ovarian tumor antigens represents a therapeutic opportunity, DC vaccination may not be clinically effective in the face of substantial barriers imposed by immune suppression in the tumor micro-environment. Direct depletion of tumor-associated Treg has often been the favored means of alleviating immune suppression in support of DC vaccination or other tumor vaccine strategies. Depletion of Treg activity may be achieved by treatment with low dose cyclophosphamide or denileukin diftitox (ONTAK) $(37,38)$. The ability of cyclophosphamide to inhibit Treg and boost anti-tumor immunity has been known for decades (39), and this drug is now widely used as an 


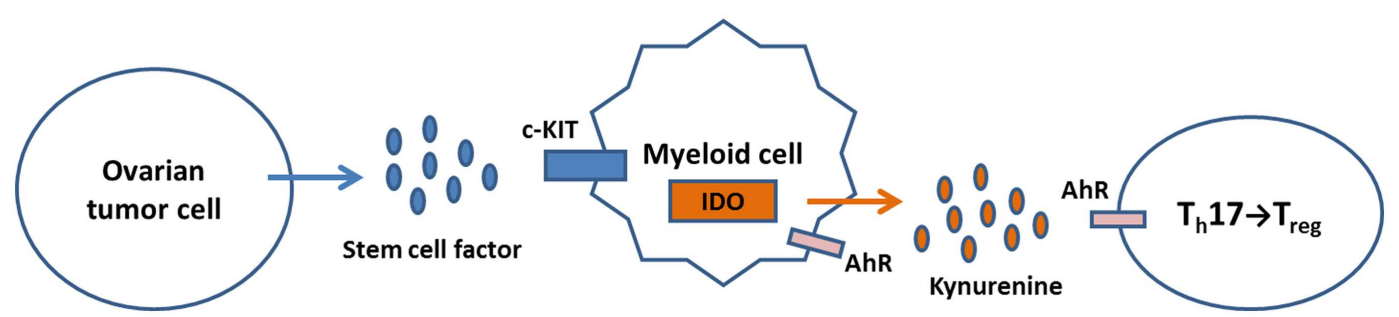

FIGURE 2 | A model for regulation of IDO expression and Treg/Th17 immunity in the ovarian tumor micro-environment. Tumor production of SCF activates C-KIT signaling in TAM, leading to induction of IDO expression.
The tryptophan catabolite kynurenine binds AhR on T cells, which shifts the Th17/Treg balance in favor of Treg generation. Kynurenine can also bind AhR on myeloid cells, further inducing IDO expression through a feedback loop. adjuvant to tumor vaccination in clinical trials. Recent studies have shown that cyclophosphamide promotes Th17 responses in cancer patients (40), lending further credence to its use as an adjuvant for DC vaccination against ovarian cancer.

A more favorable and durable approach may be to alleviate tumor-associated immune suppression through modulation of myeloid cell function and/or inhibition of IDO. If we accept the proposed model for regulation of IDO expression and Treg generation as a working hypothesis, we can infer that agents with the ability to inhibit c-KIT/PI3K/AKT/mTOR signaling or otherwise modify myeloid cell function may reduce IDO activity and inhibit recruitment of Treg in the ovarian tumor micro-environment. Our focus will be on drugs that are FDA-approved for other indications and have shown the ability to alleviate immune suppression and/or boost the efficacy of tumor vaccines or immune therapy in animal models. Promising candidates include imatinib mesylate, sunitinib, temsirolimus, and zoledronate, all of which have significant potential as adjuvants for DC vaccination against ovarian cancer.

Imatinib mesylate (Gleevec) binds BCR-ABL and c-KIT, and is an effective treatment for $\mathrm{BCR}-\mathrm{ABL}^{+}$chronic myeloid leukemia. More recent studies have shown that the therapeutic effect of imatinib could also be attributed to immune response, overcoming tumor-associated $\mathrm{T}$ cell tolerance and boosting vaccine efficacy (41). Imatinib also decreased Treg frequencies and enhanced antitumor immune responses to DC vaccination against imatinibresistant BCR-ABL-negative lymphoma (42), and was subsequently shown to activate $\mathrm{CD} 8^{+} \mathrm{T}$ cells and induce Treg apoptosis in a gastrointestinal tumor model through c-KIT inhibition and diminished IDO expression (35).

With respect to ovarian cancer, KIT ligand (SCF) is antiapoptotic and increases cisplatin resistance, whereas imatinib induces apoptosis (43). Although imatinib has shown minimal clinical benefit as a single agent in ovarian cancer $(44,45)$, it is well tolerated, and its ability to inhibit c-KIT and block IDO expression (35) suggests imatinib has potential to alleviate immune suppression as an adjuvant treatment for DC vaccination.

Sunitinib is an inhibitor of VEGFR, PDGFR, c-KIT, and Flt-3, and is FDA-approved for metastatic renal cell cancer. Sunitinib is currently being tested in over 300 clinical trials for cancer treatment $(46)$, including ovarian cancer $(47,48)$. Numerous studies have shown that sunitinib can reduce myeloid suppressor cell accumulation and decrease Treg frequencies in animal models $(49,50)$ and in renal cell carcinoma patients $(51,52)$. This activity may at least in part be mediated through c-KIT and/or STAT3 signaling $(49,50)$. Sunitinib has been tested in combination with DC loaded with autologous total tumor RNA in a recently completed phase II clinical trial (NCT00678119), and a new phase III trial of DC vaccination for renal cell carcinoma following first-line treatment with sunitinib has recently been initiated (NCT01582672). No results have been reported to date for either trial.

Axitinib, a related tyrosine kinase inhibitor that blocks multiple targets, including c-KIT, may also have potential as adjuvant therapy for DC vaccination. Axitinib was approved by the FDA in 2012, as a second line treatment for advanced renal cell carcinoma.

Rapamycin (an mTOR inhibitor) is well known for its ability to suppress $\mathrm{T}$ cell responses, but it also has potential as an anticancer agent through inhibition of HIF-1, HIF-2, and VEGF. mTOR is a downstream component of the KIT-PI3K-AKT pathway, and rapamycin can reproduce imatinib-mediated reduction of IDO (35). Temsirolimus (a rapamycin analog) was FDA-approved for the treatment of renal cancer in 2007, and is first-line treatment for patients with metastatic disease. Remarkably, temsirolimus can enhance the efficacy of tumor vaccines (53), suggesting that it does not share the immunosuppressive properties of rapamycin, and may have value as an adjuvant for DC vaccination.

Although they don't act as inhibitors of c-KIT or downstream signaling, amino-bisphosphonates may also have potential as adjuvant treatments, by virtue of their ability to modify myeloid cell function. Zoledronic acid is a matrix metalloprotease inhibitor that blocks myeloid-derived suppressor cell expansion (54) and induces a pro-inflammatory shift in macrophage function, favoring M1 polarization over the pro-tumor M2 phenotype. Zoledronate can reduce expression of VEGF and IL-10 and increase production of type- 1 cytokines such as $\operatorname{IFN} \gamma(55,56)$. It is not known whether amino-bisphosphonates have any influence on IDO expression.

\section{DIRECT INHIBITION OF IDO}

While it would appear reasonable to block IDO function directly, rather than use signal transduction inhibitors that might lead to off-target effects and toxicity, agents that inhibit IDO activity are few and far between. 1-Methyl tryptophan has seen extensive experimental use as a competitive blocker of IDO function $(57,58)$, but its clinical use has been limited. There are currently two trials of DC vaccination combined with 1-methyl 
tryptophan listed by ClinicalTrials.gov: a phase I/II trial of adenovirus p53-transduced DC vaccine with 1-methyl tryptophan for treatment of recurrent/stage IV breast cancer (NCT01042535, sponsored by the National Cancer Institute), and a phase II trial of Sipuleucel-T (Provenge ${ }^{\circledR}$, Dendreon Corp.) with 1-methyl tryptophan for treatment of metastatic castration-resistant prostate cancer (NCT01560923, sponsored by the Masonic Cancer Center, University of Minnesota).

A second agent, INCB24360, developed by Incyte Corporation, is being tested in a phase II trial versus tamoxifen for patients with ovarian, primary peritoneal, or fallopian tube cancer and suffering biochemical recurrence, i.e., with CA125 at least twice the upper limit of normal (NCT01685255). INCB24360 is also being tested in a randomized phase II trial of ipilimumab plus INCB24360 or placebo for metastatic melanoma (NCT01604889). Should INCB24360 demonstrate efficacy in inhibition of IDO activity in the clinical setting, it may have considerable value as an adjuvant treatment for DC vaccination against ovarian cancer and other malignancies.

\section{CONCLUSION}

Elucidation of the multiple facets of immune regulation in the ovarian tumor micro-environment has sharpened the appreciation that there are formidable barriers to therapeutic DC vaccination, but has also raised the prospect for mechanism-based interventions. The observations that Treg infiltration or Th17 infiltration respectively correlate with either diminished or improved overall survival strongly indicate that blockade of Treg activity or stimulation of Th17 responses could similarly result in improved clinical outcomes. DC vaccine strategies that bias tumor-specific $\mathrm{T}$ cell responses toward a Th17 phenotype should be tested in clinical trials, preferably in advanced stage ovarian cancer patients that have completed surgery and chemotherapy and have minimal disease at the time of DC vaccination. The goal should be to prevent disease recurrence or progression, rather than to use DC vaccination as a salvage therapy in patients with significant tumor burden.

Although DC vaccination designed to boost Th17 immunity represents a step forward, adjuvant treatments that alleviate tumor-associated immune suppression are probably essential for any prospect of clinical success. IDO expression by ovarian tumor cells or infiltrating myeloid cells arguably forms one of the cornerstones of immune regulation in ovarian cancer, and it is no surprise that high IDO expression is associated with diminished overall survival. Drugs that block IDO expression or activity may tip the Treg/Th17 balance in favor of anti-tumor immunity, and several intriguing possibilities that are either FDA-approved for other indications or are currently in clinical trials have been considered. Targeting of the IDO/kynurenine/AhR regulatory pathway may also be an innovative approach, e.g., through the use of AhR antagonists such as resveratrol.

Other treatments that can have an impact on immune regulation in ovarian cancer should also be considered, either as stand-alone therapy or in combination with DC vaccination. Ipilimumab targets the T cell inhibitory molecule CTLA-4, which is highly expressed by Treg, and is FDA-approved for treatment of metastatic melanoma. There are many clinical trials in progress for ipilimumab in treatment of other malignancies, including ovarian cancer, but results have been variable and often discouraging. The prospects might be better for anti-PD-1 antibodies or anti-PD-L1 antibodies, for which promising results have been reported from clinical trials. Given that PD-L1 (B7-H1) expression is associated with decreased overall survival in ovarian cancer, blockade of PDL1, or PD-1 may be an attractive option. Collectively, though, it is our opinion that the weight of evidence points to IDO as the focal target for immunological intervention in support of DC vaccination against ovarian cancer.

\section{AUTHOR CONTRIBUTIONS}

Hannah E. Goyne and Martin J. Cannon contributed equally to the preparation and writing of this manuscript.

\section{ACKNOWLEDGMENTS}

The authors were supported by funding from the Mary Kay Foundation (009-11).

\section{REFERENCES}

1. Zhang L, Conejo-Garcia JR, Katsaros D, Gimotty PA, Massobrio M, Regnani G, et al. Intratumoral $\mathrm{T}$ cells, recurrence, and survival in epithelial ovarian cancer. N Engl J Med (2003) 348:203-13. doi:10.1056/NEJMoa020177

2. Curiel TJ, Coukos G, Zou L, Alvarez X, Cheng P, Mottram P, et al. Specific recruitment of regulatory $\mathrm{T}$ cells in ovarian carcinoma fosters immune privilege and predicts reduced survival. Nat Med (2004) 10:942-9. doi:10.1038/nm1093

3. Wolf D, Wolf AM, Rumpold H, Fiegl H, Zeimet AG, Muller-Holzner E, et al. The expression of the regulatory $\mathrm{T}$ cell-specific forkhead box transcription factor FoxP3 is associated with poor prognosis in ovarian cancer. Clin Cancer Res (2005) 11:8326-31. doi:10.1158/1078-0432.CCR-05-1244

4. Sato E, Olson SH, Ahn J, Bundy B, Nishikawa H, Qian F, et al. Intraepithelial $\mathrm{CD} 8+$ tumor-infiltrating lymphocytes and a high $\mathrm{CD} 8+/$ regulatory $\mathrm{T}$ cell ratio are associated with favorable prognosis in ovarian cancer. Proc Natl Acad Sci U $S$ A (2005) 102:18538-43. doi:10.1073/pnas.0509182102

5. Dong H, Strome SE, Salomao DR, Tamura H, Hirano F, Flies DB, et al. Tumorassociated B7-H1 promotes T-cell apoptosis: a potential mechanism of immune evasion. Nat Med (2002) 8:793-800. doi:10.1038/nm730

6. Curiel TJ, Wei S, Dong H, Alvarez X, Cheng P, Mottram P, et al. Blockade of B7$\mathrm{H} 1$ improves myeloid dendritic cell-mediated antitumor immunity. Nat Med (2003) 9:562-7. doi:10.1038/nm863

7. Wang L, Pino-Lagos K, de Vries VC, Guleria I, Sayegh MH, Noelle RJ. Programmed death 1 ligand signaling regulates the generation of adaptive Foxp3+CD4+ regulatory T cells. Proc Natl Acad Sci U S A (2008) 105:9331-6. doi:10.1073/pnas.0710441105

8. Sharma MD, Hou DY, Liu Y, Koni PA, Metz R, Chandler P, et al. Indoleamine 2,3dioxygenase controls conversion of Foxp3+ Tregs to TH17-like cells in tumordraining lymph nodes. Blood (2009) 113:6102-11. doi:10.1182/blood-2008-12195354

9. Chung DJ, Rossi M, Romano E, Ghith J, Yuan J, Munn DH, et al. Indoleamine 2,3-dioxygenase-expressing mature human monocyte-derived dendritic cells expand potent autologous regulatory T cells. Blood (2009) 114:555-63. doi:10. 1182/blood-2008-11-191197

10. Hamanishi J, Mandai M, Iwasaki M, Okazaki T, Tanaka Y, Yamaguchi K, et al. Programmed cell death 1 ligand 1 and tumor-infiltrating CD8+ T lymphocytes are prognostic factors of human ovarian cancer. Proc Natl Acad Sci U S A (2007) 104:3360-5. doi:10.1073/pnas.0611533104

11. Okamoto A, Nikaido T, Ochiai K, Takakura S, Saito M, Aoki Y, et al. Indoleamine 2,3-dioxygenase serves as a marker of poor prognosis in gene expression profiles of serous ovarian cancer cells. Clin Cancer Res (2005) 11:6030-9. doi:10.1158/1078-0432.CCR-04-2671

12. Inaba T, Ino K, Kajiyama H, Yamamoto E, Shibata K, Nawa A, et al. Role of the immunosuppressive enzyme indoleamine 2,3-dioxygenase in the progression of ovarian carcinoma. Gynecol Oncol (2009) 115:185-92. doi:10.1016/j.ygyno. 2009.07.015 
13. Kryczek I, Banerjee M, Cheng P, Vatan L, Szeliga W, Wei S, et al. Phenotype, distribution, generation, and functional and clinical relevance of Th17 cells in the human tumor environments. Blood (2009) 114:1141-9. doi:10.1182/blood2009-03-208249

14. Munn DH. Th17 cells in ovarian cancer. Blood (2009) 114:1134-5. doi:10.1182/ blood-2009-06-224246

15. Cannon MJ, Goyne H, Stone PJB, Chiriva-Internati M. Dendritic cell vaccination against ovarian cancer - tipping the Treg/Th17 balance to therapeutic advantage? Expert Opin Biol Ther (2011) 11:1-5. doi:10.1517/14712598.2011.554812

16. Hargadon KM. Tumor-altered dendritic cell function: implications for antitumor immunity. Front Immunol (2013) 4:192. doi:10.3389/fimmu.2013.00192

17. Jackson AM, Mulcahy LA, Zhu XW, O'Donnell D, Patel PM. Tumour-mediated disruption of dendritic cell function: inhibiting the MEK1/2-p44/42 axis restores IL-12 production and Thl-generation. Int J Cancer (2008) 123:623-32. doi:10.1002/ijc. 23530

18. Zhao F, Falk C, Osen W, Kato M, Schadendorf D, Umansky V. Activation of p38 mitogen-activated protein kinase drives dendritic cells to become tolerogenic in ret transgenic mice spontaneously developing melanoma. Clin Cancer Res (2009) 15:4382-90. doi:10.1158/1078-0432.CCR-09-0399

19. Wang S, Hong S, Yang J, Qian J, Zhang X, Shpall E, et al. Optimizing immunotherapy in multiple myeloma: restoring the function of patients' monocyte-derived dendritic cells by inhibiting p38 or activating MEK/ERK MAPK and neutralizing interleukin-6 in progenitor cells. Blood (2006) 108:4071-7. doi:10.1182/ blood-2006-04-016980

20. Jarnicki AG, Conroy H, Brereton C, Donnelly G, Toomey D, Walsh K, et al. Attenuating regulatory $\mathrm{T}$ cell induction by TLR agonists through inhibition of $\mathrm{p} 38$ MAPK signaling in dendritic cells enhances their efficacy as vaccine adjuvants and cancer immunotherapeutics. J Immunol (2008) 180:3797-806.

21. Brereton CF, Sutton CE, Lalor SJ, Lavelle EC, Mills KH. Inhibition of ERK MAPK suppresses IL-23- and IL-1-driven IL-17 production and attenuates autoimmune disease. J Immunol (2009) 183:1715-23. doi:10.4049/jimmunol.0803851

22. Cannon MJ, Goyne H, Stone PJB, MacDonald LJ, James LE, Cobos E, et al. Modulation of p38 MAPK signaling enhances dendritic cell activation of human $\mathrm{CD}^{+}{ }^{+}$Th17 responses to ovarian tumor antigen. Cancer Immunol Immunother (2013) 62:839-49. doi:10.1007/s00262-013-1391-0

23. Baban B, Chandler PR, Sharma MD, Pikhala J, Koni PA, Munn DH, et al. IDO activates regulatory $\mathrm{T}$ cells and blocks their conversion into Th17-like $\mathrm{T}$ cells. J Immunol (2009) 183:2475-83. doi:10.4049/jimmunol.0900986

24. Funatake CJ, Marshall NB, Steppan LB, Mourich DV, Kerkvliet N. Cutting edge: activation of the aryl hydrocarbon receptor by 2,3,7,8-tetrachlorodibenzo-pdioxin generates a population of $\mathrm{CD} 4{ }^{+} \mathrm{CD} 25^{+}$cells with characteristics of regulatory T cells. J Immunol (2005) 175:4184-8.

25. Gandhi R, Kumar D, Burns EJ, Nadeau M, Dake B, Laroni A, et al. Activation of the aryl hydrocarbon receptor induces human type 1 regulatory $\mathrm{T}$ cell-like and Foxp $^{+}$regulatory T cells. Nat Immunol (2010) 11:846-53. doi:10.1038/ni.1915

26. Marshall NB, Kerkvliet NI. Dioxin and immune regulation: emerging role of aryl hydrocarbon receptor in the generation of regulatory T cells. Ann N Y Acad Sci (2010) 1183:25-37. doi:10.1111/j.1749-6632.2009.05125.x

27. Veldhoen M, Hirota K, Westendorf AM, Buer J, Dumoutier L, Renauld J-C, et al. The aryl hydrocarbon receptor links $\mathrm{T}_{\mathrm{H}}$ 17-cell-mediated autoimmunity to environmental toxins. Nature (2008) 453:106-9. doi:10.1038/nature06881

28. Quintana FJ, Basso AS, Iglesias AH, Korn T, Farex MF, Bettelli E, et al. Control of $\mathrm{T}(\mathrm{reg})$ and $\mathrm{T}(\mathrm{H}) 17$ cell differentiation by the aryl hydrocarbon receptor. Nature (2008) 453:65-71. doi:10.1038/nature06880

29. Mezrich JD, Fechner JH, Zhang X, Johnson BP, Burlingham WJ, Bradfield CA. An interaction between kynurenine and the aryl hydrocarbon receptor can generate regulatory T cells. J Immunol (2010) 185:3190-8. doi:10.4049/jimmunol. 0903670

30. Opitz CA, Litzenburger UM, Sahm F, Ott M, Tritschler I, Trump S, et al. An endogenous tumour-promoting ligand of the human aryl hydrocarbon receptor. Nature (2011) 478:197-203. doi:10.1038/nature10491

31. Nguyen NT, Kimura A, Nakahama T, Chinen I, Masuda K, Nohara K, et al. Aryl hydrocarbon receptor negatively regulates dendritic cell immunogenicity via a kynurenine-dependent mechanism. Proc Natl Acad Sci U S A (2010) 107:19961-6. doi:10.1073/pnas.1014465107

32. Inoue M, Kyo S, Fujita M, Enomoto T, Kondoh G. Coexpression of the c-kit receptor and the stem cell factor in gynecological tumors. Cancer Res (1994) 54:3049-53.
33. Parrott JA, Kim G, Skinner MK. Expression and action of kit ligand/stem cell factor in normal human and bovine ovarian surface epithelium and ovarian cancer. Biol Reprod (2000) 62:1600-9. doi:10.1095/biolreprod62.6.1600

34. Wilczynski SP, Chen Y-Y, Chen W, Howell SB, Shively JE, Alberts DS. Expression and mutational analysis of tyrosine kinase receptors c-kit, PDGFR $\alpha$, and PDGFR $\beta$ in ovarian cancers. Hum Pathol (2005) 36:242-9. doi:10.1016/ j.humpath.2004.11.009

35. Balachandran VP, Cavnar MJ, Zeng S, Bamboat ZM, Ocuin LM, Obaid H, et al. Imatinib potentiates antitumor $\mathrm{T}$ cell responses in gastrointestinal stromal tumor through the inhibition of Ido. Nat Med (2011) 17:1094-100. doi: $10.1038 / \mathrm{nm} .2438$

36. Pan P-Y, Wang GX, Yin B, Ozao J, Ku T, Divino CM, et al. Reversion of immune tolerance in advanced malignancy: modulation of myeloid-derived suppressor cell development by blockade of stem-cell factor function. Blood (2008) 111:219-28. doi:10.1182/blood-2007-04-086835

37. Kandalaft LE, Singh N, Liao JB, Facciabene A, Berek JS, Powell DJ Jr, et al. The emergence of immunomodulation: combinatorial immunotherapy opportunities for the next decade. Gynecol Oncol (2010) 116:222-33. doi:10.1016/j.ygyno. 2009.11.001

38. Goyne H, Stone PJ, Cannon MJ. Combinatorial strategies for alleviation of tumor-associated immune suppression and therapeutic vaccination against ovarian cancer. Immunotherapy (2011) 3:805-7. doi:10.2217/imt.11.71

39. North RJ. Cyclophosphamide-facilitated adoptive immunotherapy of an established tumor depends on elimination of tumor-induced suppressor T cells. J Exp Med (1982) 155:1063-74. doi:10.1084/jem.155.4.1063

40. Viaud S, Flament C, Zoubir M, Pautier P, LeCesne A, Ribrag V, et al. Cyclophosphamide induces differentiation of Th17 cells in cancer patients. Cancer Res (2011) 71:661-5. doi:10.1158/0008-5472.CAN-10-1259

41. Wang H, Cheng F, Cuenca A, Horna P, Zheng Z, Bhalla K, et al. Imatinib mesylate (STI-571) enhances antigen-presenting cell function and overcomes tumorinduced CD4 ${ }^{+}$T-cell tolerance. Blood (2005) 105:1135-43. doi:10.1182/blood2004-01-0027

42. Larmonier N, Janikashvili N, LaCasse CJ, Larmonier CB, Cantrell J, Situ E, et al. Imatinib mesylate inhibits $\mathrm{CD} 4{ }^{+} \mathrm{CD} 25^{+}$regulatory $\mathrm{T}$ cell activity and enhances active immunotherapy against BCR-ABL- tumors. J Immunol (2008) 181:6955-63.

43. Shaw T, Vanderhyden BC. AKT mediates the pro-survival effects of KIT in ovarian cancer cells and is a determinant of sensitivity to imatinib mesylate. Gynecol Oncol (2007) 105:122-31. doi:10.1016/j.ygyno.2006.10.052

44. Coleman RL, Broaddus RR, Bodurka DC, Wolf JK, Burke TW, Kavanagh JJ, et al. Phase II trial of imatinib mesylate in patients with recurrent platinumand taxane-resistant epithelial ovarian and primary peritoneal cancers. Gynecol Oncol (2006) 101:126-31. doi:10.1016/j.ygyno.2005.09.041

45. Schilder RJ, Sill MW, Lee RB, Shaw TJ, Senterman MK, Klein-Szanto AJ, et al. Phase II evaluation of imatinib mesylate in the treatment of recurrent or persistent epithelial ovarian or primary peritoneal carcinoma: a Gynecologic Oncology Group Study. J Clin Oncol (2008) 26:3418-25. doi:10.1200/JCO.2007.14. 3420

46. Ott PA, Adams S. Small-molecule protein kinase inhibitors and their effects on the immune system: implications for cancer treatment. Immunotherapy (2011) 3:213-27. doi:10.2217/imt.10.99

47. Anglesio MS, George J, Kulbe H, Friedlander M, Rischin D, Lemech C, et al. IL6STAT3-HIF signaling and therapeutic response to the angiogenesis inhibitor sunitinib in ovarian clear cell cancer. Clin Cancer Res (2011) 17:2538-48. doi:10.1158/1078-0432.CCR-10-3314

48. Biagi JJ, Oza AM, Chachal HI, Grimshaw R, Ellard SL, Lee U, et al. A phase II study of sunitinib in patients with recurrent epithelial ovarian and primary peritoneal carcinoma: an NCIC Clinical Trials Group Study. Ann Oncol (2011) 22:335-40. doi:10.1093/annonc/mdq357

49. Xin H, Zhang C, Herrmann A, Du Y, Figlin R, Yu H. Sunitinib inhibition of Stat3 induces renal cell carcinoma tumor cell apoptosis and reduces immunosuppressive cells. Cancer Res (2009) 69:2506-13. doi:10.1158/0008-5472.CAN-08-4323

50. Ozao-Choy J, Ma G, Kao J, Wang GX, Meseck M, Sung M, et al. The novel role of tyrosine kinase inhibitor in the reversal of immune suppression and modulation of tumor microenvironment for immune-based cancer therapies. Cancer Res (2009) 69:2514-22. doi:10.1158/0008-5472.CAN-08-4709

51. Finke JH, Rini B, Ireland J, Rayman P, Richmond A, Golshayan A, et al. Sunitinib reverses type-1 immune suppression and decreases T-regulatory 
cells in renal cell carcinoma patients. Clin Cancer Res (2008) 14:6674-82. doi:10.1158/1078-0432.CCR-07-5212

52. Ko JS, Zea AH, Rini BR, Ireland JI, Elson P, Cohen P, et al. Sunitinib mediates reversal of myeloid-derived suppressor cells accumulation in renal cell carcinoma patients. Clin Cancer Res (2009) 15:2148-57. doi:10.1158/1078-0432. CCR-08-1332

53. Wang Y, Wang X-Y, Subjeck JR, Shikant P, Kim HL. Temsirolimus, and mTOR inhibitor, enhances anti-tumour effects of heat shock protein cancer vaccines. Br J Cancer (2011) 104:643-52. doi:10.1038/bjc.2011.15

54. Melani C, Sangaletti S, Barazzetta FM, Werb Z, Colombo MP. Aminobiphosphonate-mediated MMP-9 inhibition breaks the tumor-bone marrow axis responsible for myeloid-derived suppressor cell expansion and macrophage infiltration in tumor stroma. Cancer Res (2007) 67:11438-46. doi:10.1158/00085472.CAN-07-1882

55. Tsagozis P, Eriksson F, Pisa P. Zoledronic acid modulates antitumoral responses of prostate cancer-tumor associated macrophages. Cancer Immunol Immunother (2008) 57:1451-9. doi:10.1007/s00262-008-0482-9

56. Coscia M, Quaglino E, Iezzi M, Curcio C, Pantaleoni F, Riganti C, et al. Zoledronic acid repolarizes tumour-associated macrophages and inhibits mammary carcinogenesis by targeting the mevalonate pathway. J Cell Mol Med (2010) 14:2803-15. doi:10.1111/j.1582-4934.2009.00926.x

57. Hou D-Y, Muller AJ, Sharma MD, DuHadaway J, Banerjee T, Jihnson M, et al. Inhibition of indoleamine 2,3-dioxygenase in dendritic cells by stereoisomers of 1-methyl-tryptophan correlates with antitumor responses. Cancer Res (2007) 67:792-801. doi:10.1158/0008-5472.CAN-06-2925
58. Qian F, Villella J, Wallace PK, Mhawech-Fauceglia P, Tario JD Jr, Andrews C, et al. Efficacy of levo-1-methyl tryptophan and dextro-1-methyl tryptophan in reversing indoleamine-2,3-dioxygenase-mediated arrest of $\mathrm{T}$ cell proliferation in human epithelial ovarian cancer. Cancer Res (2009) 69:5498-504. doi:10.1158/0008-5472.CAN-08-2106

Conflict of Interest Statement: Martin J. Cannon is a founder of DCV Technologies, Inc., a biotechnology company dedicated to the clinical development of dendritic cell vaccines for the treatment of cancer. The authors declare no other conflicts of interest.

Received: 30 September 2013; accepted: 04 November 2013; published online: 18 November 2013.

Citation: Goyne HE and Cannon MJ (2013) Dendritic cell vaccination, immune regulation, and clinical outcomes in ovarian cancer. Front. Immunol. 4:382. doi: 10.3389/fimmu.2013.00382

This article was submitted to Tumor Immunity, a section of the journal Frontiers in Immunology.

Copyright (C) 2013 Goyne and Cannon. This is an open-access article distributed under the terms of the Creative Commons Attribution License (CC BY). The use, distribution or reproduction in other forums is permitted, provided the original author (s) or licensor are credited and that the original publication in this journal is cited, in accordance with accepted academic practice. No use, distribution or reproduction is permitted which does not comply with these terms. 